\title{
Tratamento térmico e prochloraz no controle da antracnose em pós-colheita de frutos de banana 'Prata Anã'
}

\author{
Marcelo Barreto da Silva ${ }^{1}$, Alexandre Sylvio Vieira da Costa ${ }^{1}$, José Carlos Moraes Rufini ${ }^{1}$, Eduardo Rezende \\ Galvão ${ }^{1}$, Laércio Zambolim²
}

${ }^{1}$ Faculdade de Ciências Agrárias da Universidade Vale do Rio Doce, Cx Postal 295, CEP 35020-200, Governador Valadares, MG, e-mail: mbarreto@univale.br; ${ }^{2}$ Departamento de Fitopatologia da Universidade Federal de Viçosa, CEP 35270-000, Viçosa, MG.

Autor para correspondência:

Data de chegada: 20/05/2006. Aceito para publicação em: 22/10/2007

\section{RESUMO}

Silva, M. B.; Costa, A. S. V.; Rufini, J. C. M.; Galvão, E. R.; Zambolim, L. Tratamento térmico e prochloraz no controle da antracnose em póscolheita de frutos de banana 'Prata Anã'.Summa Phytopathologica, v.34, n.4, p.364-365, 2008

O controle químico, térmico e a refrigeração são os processos mais utilizados no tratamento pós-colheita das bananas. O objetivo deste trabalho foi avaliar o efeito do tratamento térmico, químico e da combinação dos dois métodos e estes associados à baixa temperatura de conservação no controle da antracnose na pós-colheita da banana. Para tanto os experimentos foram realizados em três épocas quando, bananas (Musa sp) da variedade 'Prata Anã' (AAB) no estádio préclimatérico eram coletadas e suas pencas individualizadas. As pencas foram submetidas a quatro tratamentos com cinco repetições cada: 1. Tratamento térmico (imersão em água a $56^{\circ} \mathrm{C}$ por seis minutos, seguido de resfriamento em água à temperatura ambiente); 2. Tratamento químico por seis minutos (imersão em calda fungicida (prochloraz 2,5 $\left.\mathrm{mL} . \mathrm{L}^{-1}\right)$ ); 3. Tratamento térmico seguido do químico; 4. Testemunha, imersão em água por seis minutos. Após os tratamentos, as pencas eram divididas em duas partes iguais, sendo que uma parte ficou em câmara fria $\left(14^{\circ} \mathrm{C}\right.$ com variação de $\left.2^{\circ} \mathrm{C}\right)$ e a outra permaneceu à temperatura ambiente. $\mathrm{O}$ tratamento térmico não foi eficiente no controle da doença. O fungicida prochloraz a $2,5 \mathrm{~mL} . \mathrm{L}^{-1}$ foi eficiente no controle da podridão pós-colheita. A refrigeração retardou o surgimento da doença em até 12 dias. Os resultados indicam que a baixa temperatura, associada ou não ao controle químico, é capaz de controlar a podridão pós-colheita dos frutos por 12 dias.

Palavras-chave adicionais: Colletotrichum musae, Musa sp, prochloraz, Antracnose

\section{ABSTRACT}

Silva, M. B.; Costa, A. S. V.; Rufini, J. C. M.; Galvão, E. R.; Zambolim, L. Thermotherapy and prochloraz to control of anthracnose on 'Prata Anã' bananas in post harvest conditions. Summa Phytopathologica, v.34, n.4, p.364-365, 2008

Chemical control and refrigeration are two processes usually adopted in the treatment of the banana post harvest rot. This work has for objective to evaluate the effect on the control of the anthracnose in banana post harvest of the chemotherapy, of the thermotherapy, of the combination of the two listed methods and these all associated to the low conservation temperature. The experiments were replicate three times where banana fruit (Musa sp) of the variety 'Prata Anã' (AAB) were collected in the pre-climateric stage. The fruits were submitted to four treatments with five replications. 1. thermotherapy (immersion in hot water at $56^{\circ} \mathrm{C}$ for six minutes, followed by immersion in water at home temperature), 2. chemical control for six minutes (immersion in fungicidal suspension (prochloraz $2.5 \mathrm{~mL} . \mathrm{L}-1$ )), 3. thermotherapy followed by the chemical control, 4. Negative control, immersion water at home temperature for six minutes. After the treatments, the hands was divided in half parts, one part was put in cold camera $\left(14^{\circ} \mathrm{C}\right.$ with variation of $\left.\quad 2^{\circ} \mathrm{C}\right)$ and the other one stayed at home temperature. The thermotherapy wasn't effective to control of the disease. The fungicide prochloraz at $2.5 \mathrm{~mL} . \mathrm{L}^{-1}$ was efficient in the control of the banana post harvest rot. The refrigeration delayed the presence of the disease in up to 12 days. The results indicate that the low temperature, associated or not to the chemical control, can control the fruits post harvest rot for 12 days.

Keywords: Colletotrichum musae, Musa sp, prochloraz, Anthracnose

A banana é a fruta mais consumida no mundo e apresenta grande importância no mercado internacional de frutas. O controle químico, térmico e a refrigeração são os principais métodos disponíveis para reduzir a incidência de doença em pós-colheita de frutas (2). O uso de fungicidas é a base para o tratamento químico, no entanto alguns problemas têm reduzido a eficácia deste método de controle em decorrência da forma de aplicação do produto (6) e do surgimento de populações dos patógenos resistentes aos produtos utilizados $(4,5)$. O presente trabalho teve por objetivo comparar o efeito da termoterapia, do controle químico e da combinação destes sobre a ocorrência de antracnose em frutos de banana armazenados em temperatura ambiente e sob refrigeração a $14^{\circ} \mathrm{C}$.

Nos meses de fevereiro, abril e junho, bananas foram coletadas em propriedades comerciais, onde não ocorre o controle químico de pragas 
Tabela 1. Porcentagem da severidade da antracnose em bananas 'Prata Anã', colhidas em três épocas distintas, submetidas a diferentes tratamentos e duas condições de armazenagem.

\begin{tabular}{|c|c|c|c|c|c|}
\hline \multirow[b]{2}{*}{ Condições de armazenagem } & \multicolumn{5}{|c|}{ Tratamentos realizados/ Mês: fevereiro } \\
\hline & Químico & Térmico + Químico & Térmico & Testemunha & Médias \\
\hline Câmara Fria $\left(14^{\circ} \mathrm{C}\right)$ & 0,0 a $\mathrm{A}$ & 0,0 a $\mathrm{A}$ & 4,0 a $\mathrm{A}$ & 0,0 a $\mathrm{A}$ & $1,0 \quad \mathrm{a}$ \\
\hline Temperatura Ambiente $\left(20,4-24,5-30,1^{\circ} \mathrm{C}\right)^{1}$ & 0,0 a $\mathrm{A}$ & 0,6 a $\mathrm{A}$ & $72,0 \mathrm{~b} \mathrm{~B}$ & $98,0 \mathrm{~b} \quad \mathrm{C}$ & $42,7 \mathrm{~b}$ \\
\hline Médias & 0,0 & 0,3 & 38,0 & 49,0 & $\mathrm{CV}(\%)=21,1$ \\
\hline
\end{tabular}

Tratamentos realizados/ Mês: abril

\begin{tabular}{|c|c|c|c|c|c|}
\hline Condições de armazenagem & Químico & Térmico + Químico & Térmico & Testemunha & Médias \\
\hline Câmara Fria $\left(14^{\circ} \mathrm{C}\right)$ & 0,0 a $\mathrm{A}$ & 0,0 a $\mathrm{A}$ & 0,0 a $\mathrm{A}$ & 0,0 a A & $0,0 \quad \mathrm{a}$ \\
\hline Temperatura Ambiente $\left(29,6-23,5-19,0^{\circ} \mathrm{C}\right)^{2}$ & 0,8 a $\mathrm{A}$ & 0,6 a $\mathrm{A}$ & 19,3 b B & 28,8 b B & $12,4 \mathrm{~b}$ \\
\hline Médias & $0,4 \quad \mathrm{~A}$ & $0,3 \quad \mathrm{~A}$ & $9,7 \quad \mathrm{~B}$ & $14,4 \quad \mathrm{~B}$ & $\mathrm{CV}(\%)=45,1$ \\
\hline
\end{tabular}

\begin{tabular}{|c|c|c|c|c|c|}
\hline \multirow[b]{2}{*}{ Condições de armazenagem } & \multicolumn{5}{|c|}{ Tratamentos realizados/ Mês: junho } \\
\hline & Químico & Térmico + Químico & Térmico & Testemunha & Médias \\
\hline Câmara Fria $\left(14^{\circ} \mathrm{C}\right)$ & 0,0 a $\mathrm{A}$ & 0,0 a $\mathrm{A}$ & 0,0 a $\mathrm{A}$ & 0,0 a $\mathrm{A}$ & $0,0 \quad \mathrm{a}$ \\
\hline Temperatura Ambiente $\left(28,4-19,3-12,6^{\circ} \mathrm{C}\right)^{3}$ & 0,8 a $\mathrm{A}$ & 0,6 a $\mathrm{A}$ & 19,3 b B & $28,8 \mathrm{~b} \mathrm{~B}$ & $12,4 \mathrm{~b}$ \\
\hline Médias & $0,4 \quad \mathrm{~A}$ & $0,3 \quad \mathrm{~A}$ & $9,7 \quad \mathrm{~B}$ & $14,4 \quad \mathrm{~B}$ & $\mathrm{CV}(\%)=45,1$ \\
\hline
\end{tabular}

Médias seguidas por mesma letra minúscula, na coluna, e maiúscula, na linha, não diferem entre si, pelo teste de Tukey a $5 \%$ de probabilidade.

${ }^{1,2,3}$ Temperaturas (mínima, média e máxima) observadas durante o mês de fevereiro, abril e junho, respectivamente.

e doenças, localizadas no município de São Geraldo da Piedade, leste de Minas Gerais. Em laboratório, as pencas foram submetidas a diferentes tratamentos: 1) tratamento térmico, quando os buquês foram imersos em água quente a $56^{\circ} \mathrm{C}$, durante seis minutos, e resfriados em água à temperatura ambiente, durante dez minutos; 2) tratamento químico, imersão dos frutos em calda fungicida (prochloraz 2,5 mL.L 1), à temperatura ambiente, durante três minutos; 3 3) tratamento térmico mais químico, quando os buquês, após serem imersos em água à temperatura de $56^{\circ} \mathrm{C}$ por seis minutos, eram resfriados em calda fungicida (prochloraz 2,5 mL.L $\mathrm{L}^{-1}$ ), à temperatura ambiente por três minutos; 4) testemunha, imersão dos buquês em água à temperatura ambiente por dez minutos. Após o tratamento, os buquês foram colocados para secar e partidos ao meio. Metade dos buquês permaneceu à temperatura ambiente $\left(25 \pm 6^{\circ} \mathrm{C}\right)$ e a outra metade foi armazenada em câmara fria a $14 \pm 2^{\circ} \mathrm{C}$. A severidade da antracnose nos frutos foi estimada com auxílio de escala diagramática desenvolvida por Moraes (3) com variação de severidade da doença de 0,5 a $64 \%$. Cada tratamento teve cinco repetições e cada penca foi considerada como uma repetição.

As pencas do tratamento testemunha, que permaneceram armazenadas à temperatura ambiente, não se conservaram por mais de 12 dias após receber os tratamentos. Os dados utilizados para a comparação entre os tratamentos foram aqueles obtidos aos 12 dias. Nos buquês não tratados e armazenados à temperatura ambiente, a podridão pós-colheita apresentou maior intensidade, atingindo valores médios que variaram de 28,8 a $98 \%$ (Tabela 1 ). Sob resfriamento não foi possível discriminar o efeito dos tratamentos sobre a antracnose dos frutos. O armazenamento das bananas a baixa temperatura, independentemente do tratamento, reduziu significativamente a severidade da doença até os doze dias de armazenamento nas três épocas de coleta (Tabela 1). Resultados semelhantes foram obtidos por Hassan et al. (1) que obtiveram redução da severidade da podridão pós-colheita em bananas armazenadas a 10,14 e $18^{\circ} \mathrm{C}$. Acredita-se que a baixa temperatura não elimine o patógeno e sim retarde a manifestação da doença por reduzir o amadurecimento da banana e reduzir o metabolismo do fungo.
Em condições de temperatura ambiente, o tratamento térmico não foi eficiente no controle da podridão pós-colheita, não diferindo estatisticamente da intensidade da doença encontrada no tratamento sem controle nos meses de abril e junho (Tabela 1).

Em todos as épocas, o tratamento químico com o fungicida prochloraz $\left(2,5 \mathrm{~mL} . \mathrm{L}^{-1}\right)$, associado ou não ao tratamento térmico, foi o método de controle da podridão pós-colheita mais eficiente tanto para as bananas armazenadas em temperatura ambiente quanto em câmara fria (Tabela 1). A associação do controle térmico e químico não promoveu melhoria no controle da doença.

\section{AGRADECIMENTOS}

Os autores agradecem à Fundação de Amparo à Pesquisa do Estado de Minas Gerais (FAPEMIG) pelo financiamento do projeto que forneceu os dados para este artigo.

\section{REFERÊNCIAS BIBLIOGRÁFICAS}

1. Hassan, M. K., Shipton, W. A., Coventry, R., Gardiner, C. Extension of banana shelf life. Australasian Plant Pathology, Queensland, v.33, n.2, p.305-308, 2004.

2. Labavitch, J. M. Fruit ripening and defense against pathogens loss of resistance or gain of susceptibility. In: JOHSON, G. I.; HIGHLEY, E.; JOYCE, D. C. (Eds). Disease resistance in fruit. Australia: ACIAR, v.80, p.53-59, 1998.

3. Moraes, W. S. Integração de métodos de controle de podridão em pós-colheita da banana 'Prata Anã' (AAB). Viçosa: UFV, 1999. 84p. Dissertação (Doutorado) - Universidade Federal de Viçosa, 1999.

4. Sapalding, D. H.; Reeder, W. F. Postharvest disorders of mango as affected by fungicides and heat treatments. Plant Disease Reporter, St. Paul, v.56, p751-753, 1972.

5. Ventura, J. A., Balbino, J. M. S. Resistência do agente etiológico da antracnose do mamoeiro ao benomil, no Estado do Espírito Santo. Fitopatologia Brasileira, Brasília, v.19, p.297, 1994.

6. Winiewski, E.; Wilson, C. L. Biological control of post harvest disease of fruits and vegetables: Recent Advances. Hort Science, St. Joseph, v.27, p.94-98, 1992. 